\title{
The Empirical Analysis About Using Tourism to Promote the New-Type Urbanization on Ganzi Tibetan Autonomous Prefecture
}

\author{
Yang Jin, Zhao Bing \\ Southwest University for Nationalities, Architecture and Urban Planning College, Chendu, China
}

Email address:

962464167@qq.com (Yang Jin), 190288595@qq.com (Zhao Bing)

To cite this article:

Yang Jin, Zhao Bing. The Empirical Analysis About Using Tourism to Promote the New-Type Urbanization on Ganzi Tibetan Autonomous Prefecture. American Journal of Civil Engineering. Vol. 4, No. 6, 2016, pp. 351-359. doi: 10.11648/j.ajce.20160406.22

Received: November 18, 2016; Accepted: November 24, 2016; Published: December 7, 2016

\begin{abstract}
Tourism development and urbanization are the two hot economic phenomena in today's society, and are also two important aspects of social and economic development. Ganzi Tibetan Autonomous Prefecture take full advantage of its rich tourism resources, out of a tourism-driven urbanization of the new urbanization development path. In this paper, from the typical tourist town of Ganzi Tibetan Autonomous Prefecture as a starting point, through empirical analysis, it is concluded that the development of new urbanization in ethnic areas has a good propelling effect, and there are certain conditions and limitations. At the same time, it puts forward some policy suggestions for the mutual development of tourism and new urbanization in minority areas, with a view to realizing the healthy and rapid development of tourism in ethnic areas to promote the new urbanization.
\end{abstract}

Keywords: Ethnic Minority Areas, Tourism Industry, New Urbanization, Path

\section{Introduction}

For China's ethnic minority areas, and other plain areas or developed areas of new urbanization is different. Minority areas are usually in the backward areas of China's economic development, the lack of regional economic development pillar industries, tourism is usually an effective way to economic development in the region, China's ethnic minority areas to use this socio-economic phenomenon to promote new towns of the construction is particularly prominent. However, many ethnic areas of tourism and urbanization is still in its infancy, there are still many issues worth noting. Taking the Ganzi Tibetan Autonomous Prefecture as an example, this paper puts forward some strategic countermeasures and suggestions on promoting the new urbanization of the tourism industry in ethnic areas by summarizing the impetus and negative effects of the new urbanization construction in Ganzi Tibetan Autonomous Prefecture.

\section{The Present Situation of Tourist Urbanization in Ganzi Tibetan Autonomous Prefecture}

\subsection{Basic Situation of Ganzi Tibetan Autonomous Prefecture}

Ganzi Tibetan Autonomous Prefecture (GanziPrefecture) is located in the western Sichuan Province, the southeast of the Tibetan Plateau. The total area of 153,000 square kilometers, is a Tibetan as the main nation-level administrative region. (County), 2679 administrative villages, the resident population of $1,614,900$ people, is the largest county in Sichuan Province, the largest area, the population density Lowest area. The state average elevation of 3500 meters, with an average annual temperature of $7.8^{\circ} \mathrm{C}$.

\subsection{The Development of Tourism in Ganzi Tibetan Autonomous Prefecture}

\subsubsection{Travel Resources}

Ganzi Tibetan Autonomous Prefecture is rich in tourism 
resources, its special natural environment, making it a set of glaciers, snow-capped mountains, grasslands, rivers, valleys, waterfalls, springs, lakes, forests, wetlands and other natural landscape, historical monuments of Tibetan Buddhism In one area. There are national scenic spots and national AAAA-level tourist area Gongga Hill Hailuogou, Muge measures, Daocheng Aden; Gongga Hill, Chashingsong many other national nature reserves, is "China's Shangri-La Ecological Tourism Zone," the core Is the potential of tourism development in western China in the 21 st century. It has been designated by the World Tourism Organization as "China's natural eco-tourism and Khamba cultural tourism destination to the world".

\subsubsection{Development Status Quo}

From 2007-2015 Ganzi Tibetan Autonomous Prefecture tourism development level of the table, we can see that the rapid development of tourism in recent years. In 2008, by the "3.14", "5.12" and other natural and man-made disasters, the tourism industry fell sharply, the annual tourists only 1.16 million passengers, adjusted in 2009, 2.7 million tourists throughout the year, the tourism industry to achieve restorative growth. In just eight years, the number of domestic tourists jumped from 1.15 million in 2008 to 10.6867 million in 2015; the number of inbound tourists jumped from 16.1 thousand in 2008 to 75.1 thousand in 2015. In the past eight years, the total income of Ganzi Tibetan Autonomous Prefecture has been growing at the same time. The tourism industry has entered into the fast and healthy development of the interactive and orderly development, becoming the largest industry in Ganzi Tibetan Autonomous Prefecture.

Table 1. Statistics of tourism development in Ganzi Tibetan Autonomous Prefecture.

\begin{tabular}{llll}
\hline Years & Total tourism income (100 million yuan) & Gross National Product (100 million yuan) & $\begin{array}{l}\text { Tourism Development (Tourism Revenue / } \\
\text { Gross National Product) }\end{array}$ \\
\hline 2007 & 23.44 & 78.87 & $29.72 \%$ \\
2008 & 7.77 & 94 & $8.27 \%$ \\
2009 & 17.78 & 103.16 & $17.24 \%$ \\
2010 & 23.56 & 122.83 & $19.18 \%$ \\
2011 & 30 & 152.22 & $19.70 \%$ \\
2012 & 35.87 & 175 & $20.50 \%$ \\
2013 & 63.25 & 201.22 & $31.43 \%$ \\
2014 & 80.3 & 206.81 & $38.83 \%$ \\
2015 & 107.50 & 213.04 & $50.46 \%$ \\
\hline
\end{tabular}

(Source: Statistical Communiqué on National Economic and Social Development of Ganzi Tibetan Autonomous Prefecture, 2007-2015)

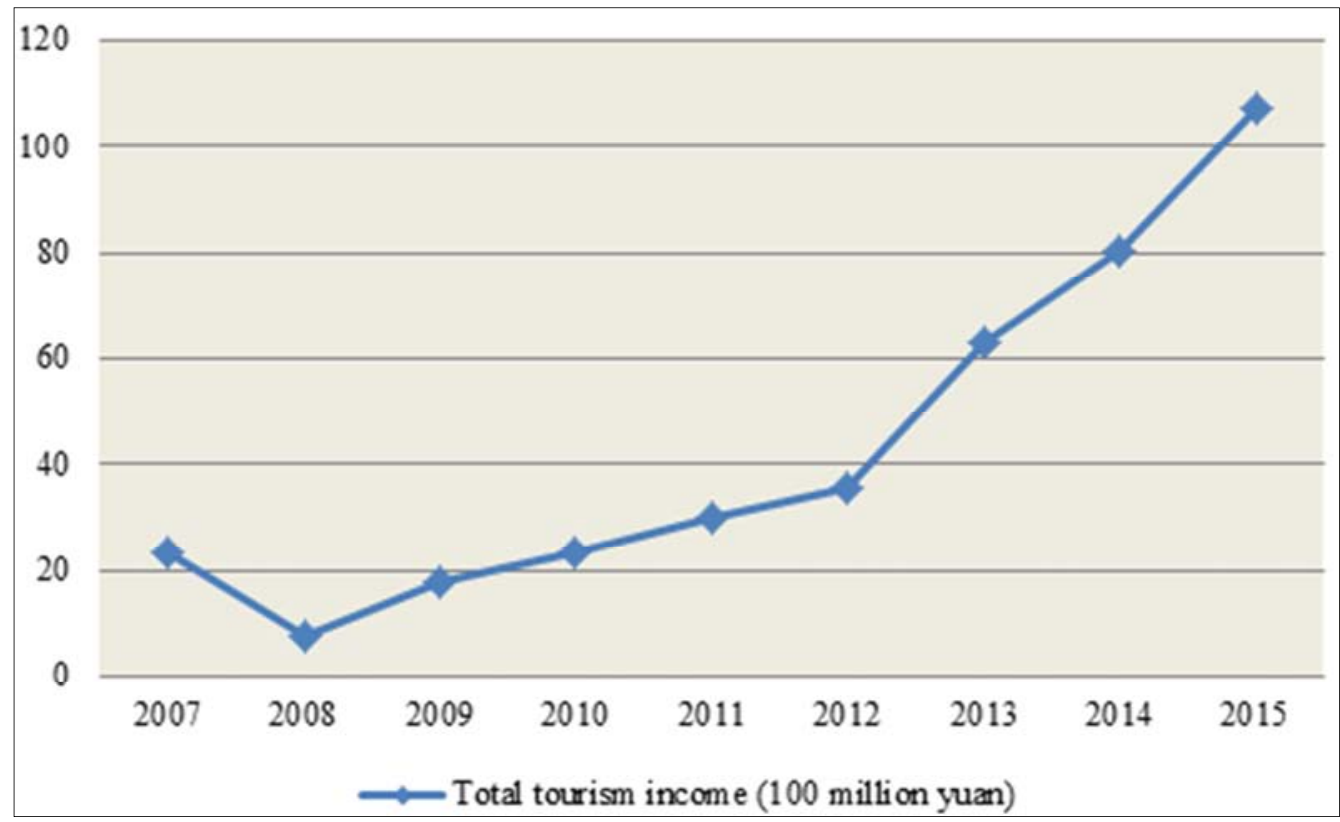

Figure 1. Statistics on the Total Tourism Revenue of Ganzi Tibetan Autonomous Prefecture(Source: Statistical Communiqué on National Economic and Social Development of Ganzi Tibetan Autonomous Prefecture, 2007-2015).

\subsection{The Present Situation of Urbanization in Ganzi Tibetan Autonomous Prefecture}

At present, the level of urbanization in Ganzi Tibetan Autonomous Prefecture has been steadily increasing. The urbanization rate in 2015 is $28.06 \%$, which is 9.04 percentage points higher than $19.02 \%$ in 2009 , with an annual growth rate of 1.29 percentage points.

However, from the Ganzi Tibetan Autonomous Prefecture and the country, Sichuan Province and Aba and Liangshan urbanization rate of horizontal comparison, the statewide total population of $1,159,900$ people in 2015, the 
urbanization rate of $28.06 \%$, lower than the national $56.10 \%$ A percentage point lower than the province's $47.69 \%$ about 19.63 percentage points. In the minority areas of Sichuan, the urbanization rate of Aba Prefecture is $36.77 \%$ in 2015 and $32.40 \%$ in Liangshan Prefecture in 2015, and the urbanization level of Ganzi Prefecture is relatively low. The proportion of urban and rural population is relatively small, so the development of cities and towns is still in urgent need of population and industry to further gather support and drive.

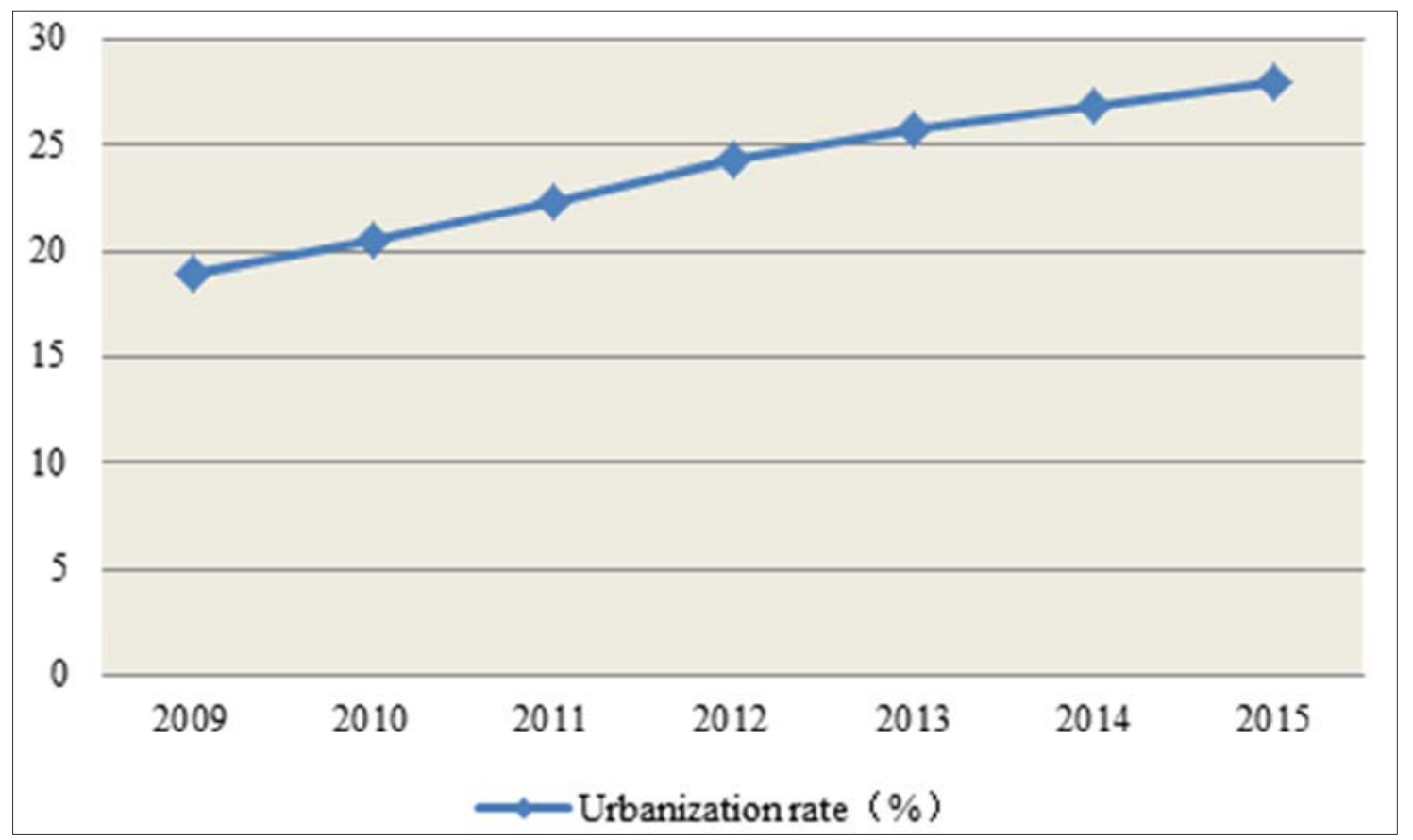

(Source: Statistical Communiqué on National Economic and Social Development of Ganzi Tibetan Autonomous Prefecture, 2009-2015)

Figure 2. Statistics on Urbanization Rate in Ganzi Tibetan Autonomous Prefecture.

Table 2. Comparison of Urbanization Rate between Ganzi Tibetan Autonomous Prefecture and National, Provincial and Three - state Regions.

\begin{tabular}{|c|c|c|c|c|c|c|c|}
\hline & 2009 & 2010 & 2011 & 2012 & 2013 & 2014 & 2015 \\
\hline China & 46.6 & 49.68 & 51.27 & 52.57 & 53.73 & 54.77 & 56.10 \\
\hline Sichuan Province & 38.7 & 40.3 & 41.83 & 43.53 & 44.90 & 46.3 & 47.69 \\
\hline Ganzi Prefecture & 19.02 & 20.53 & 22.39 & 24.41 & 25.81 & 26.87 & 28.06 \\
\hline Aba & 30 & 30 & 31.65 & 33.37 & 34.59 & 35.69 & 36.77 \\
\hline Liangshan Prefecture & 27.04 & 27.52 & 30 & - & 30.57 & 31.44 & 32.40 \\
\hline
\end{tabular}

Note: The individual data statistics incomplete, but does not affect the statistical results.

(Source: Statistical Communiqué on National Economic and Social Development of Ganzi Tibetan Autonomous Prefecture, 2009-2015)

\section{The Driving Effect of Tourism Development on New Urbanization in Ganzi Tibetan Autonomous Prefecture}

\subsection{Tourism to Promote Industrial Development and Industrial Restructuring}

Ganzi Tibetan Autonomous Prefecture of the tourism industry started relatively late. In 1998 the state received a total of 7 million tourists trips, tourism income of only 30.37 million. Before 1998, Ganzi is the initial stage of tourism, the potential advantages of the tourism industry has not yet been revealed. After 1998, the industrial structure of Ganzi Tibetan Autonomous Prefecture has been optimized, and the economic structure has been transformed from traditional agriculture and animal husbandry to eco-cultural tourism, green product processing and agricultural industrialization. The secondary and tertiary industries have become the core power of economic development. The three industrial structures are characterized by "one tow two", from 32.9: 34.6: 32.5 in 1995 to 25.5 : 35.6: 38.9 in 2015.

In recent years, Quanzhou in the new urban construction of the road against the background, make full use of its rich tourism resources to eco-tourism, rural tourism as the focus of human, tourism resources, expand cultural connotation, the tourism industry in Yu Minqiang of the strategic height. The state's tourist reception and tourism revenue year after year, the pillar of the tourism industry began to highlight, and ultimately promote the Ganzi Tibetan Autonomous Prefecture's industrial development and industrial restructuring. 


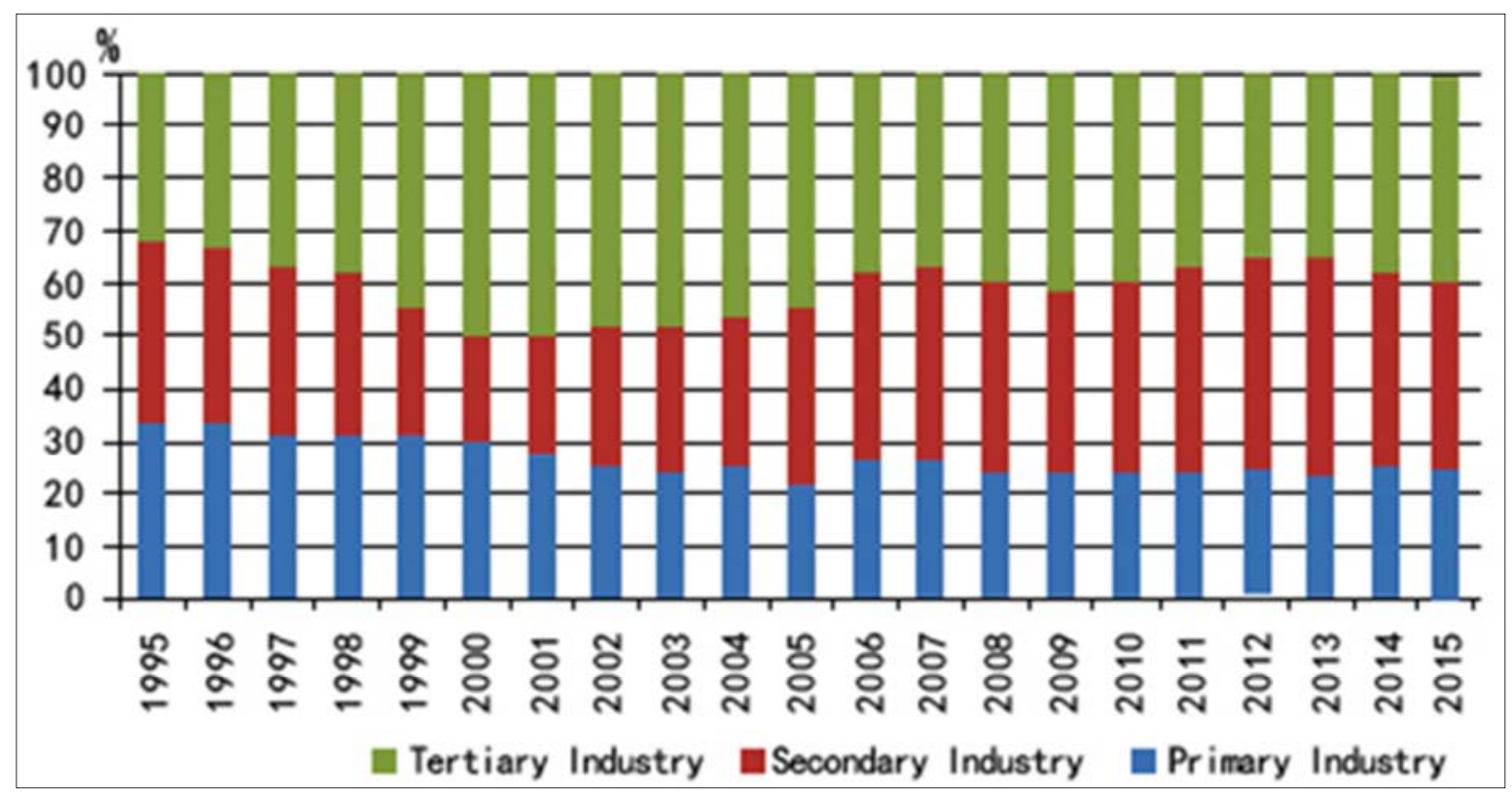

Figure 3. Ganzi Tibetan Autonomous Prefecture Industrial Structure.

(Source: Statistical Communiqué on National Economic and Social Development of Ganzi Tibetan Autonomous Prefecture, 2011-2015; Ganzi Prefecture town system planning brochure)

\subsection{Tourism to Promote the Construction of Urban Infrastructure}

With the development of tourism, Ganzi tourism income increase, for the local urbanization construction provides strong support. Tourism destination environment and strong economic agglomeration will also attract more investors to join the ranks of urban construction. Such as Kangding County Metro, with the development of tourism, the increase in the amount of tourists, creating a national characteristics, geographical characteristics, characteristics of the times and cultural characteristics of the town style.

In recent years, the government has given great care and support to the urban infrastructure construction of the Ganzi Tibetan Autonomous Prefecture. Through the implementation of county water supply, municipal solid waste sewage treatment facilities, Tibetan urban roads, bridges and other investment projects, A greater change. The urban infrastructure has been greatly improved, the urban facilities have been further improved, the overall image of the county to be a certain upgrade, the city's comprehensive power and radiation continue to increase for the county economic development and improve the quality of life provides a strong stand by. To achieve a virtuous circle of economic development and infrastructure construction, and lay a solid foundation for the sustainable development of the city's economy.As can be seen from Table 3, the infrastructure investment in Ganzi Tibetan Autonomous Prefecture has a positive correlation with the level of tourism development, the level of tourism development has increased by $11.63 \%$, and the corresponding investment in infrastructure has increased by 14.331 billion Yuan. However, for the Ganzi Tibetan Autonomous Prefecture, this increase is not significant, mainly due to location factors. Ganzi Tibetan Autonomous Prefecture's topography, topography with: North High South low, high-lying terrain, central processes and other characteristics, coupled with higher elevation, resulting in a larger investment in infrastructure construction costs.

Table 3. Ganzi Tibetan Autonomous Prefecture infrastructure investment and tourism development level, urbanization rate.

\begin{tabular}{llll}
\hline Years & Tourism Development (Tourism Revenue / Gross National Product) & Infrastructure investment (100 million yuan) & Urbanization rate \\
\hline 2007 & $29.72 \%$ & 91.32 & $16.53 \%$ \\
2008 & $8.27 \%$ & 13.03 & $18.90 \%$ \\
2009 & $17.24 \%$ & 146.33 & $19.02 \%$ \\
2010 & $19.18 \%$ & 194.28 & $21.00 \%$ \\
2011 & $19.70 \%$ & 188.8 & $22.39 \%$ \\
2012 & $20.50 \%$ & 170.81 & $24.41 \%$ \\
2013 & $31.43 \%$ & 208.25 & $25.81 \%$ \\
2014 & $38.83 \%$ & 351.56 & $26.87 \%$ \\
2015 & $50.46 \%$ & $28.06 \%$ \\
\hline
\end{tabular}

(Source: Statistical Communiqué on National Economic and Social Development of Ganzi Tibetan Autonomous Prefecture, 2007-2015) 


\subsection{Tourism to Promote the Development of Local Urbanization}

The development of tourism will promote the development of urbanization on the spot and promote the overall urban and rural development. Ganzi Tibetan Autonomous Prefecture, most of the scenic areas in rural areas, the development of tourism will bring people to gather, consumer aggregation, service aggregation. Tourism resources concentrated in the east, north, south will become an important tourist crowds. The gathering of tourist groups will bring the development of tourism-related industries, the formation of industrial integration and industrial agglomeration. Industrial agglomeration zone, to industrial workers gathered to form the original urban residents, urbanization of farmers living, industrial workers living together, living in a variety of foreign tourists living in concentrated concentration, forming the basis of urbanization, relying on industry, together with tourism Service facilities, demand and consumption of the centralization of the formation of supporting tourism infrastructure and improve the social system, etc., thus forming a local urbanization.

Ganzi Tibetan Autonomous Prefecture in accordance with the "layout of the scientific, environmental ecology, landscape pastoral, style characteristics of" requirements, to create "pastoral pastoral" type of new farmers and herdsmen village, village transformation and tourism development together to form a group of tourism Villages, cultural villages and modern villages, to promote the production factors, elements of life to the tourist town (village) concentration. Speed up the development of farm music, combined with the planning of a good herdsman settlement layout of a number of "Tibetan music" and the characteristics of family hotels, farm management and grazing farming, farming complement each other to promote the formation of their own family characteristics of industry support and income sources. Encourage mature herdsmen to withdraw from animal husbandry production and develop the employment opportunities in cities and towns through the development of industry, tourism and other three production sectors, and promote the transformation of pastoralists from simple settlers to the production and management of urban economy, from traditional decentralized production to modern Urban intensive production mode change, promote the coordinated development of urban and rural economy, and promote rural surplus labor to the town as soon as possible transfer.

\subsection{Tourism to Promote Employment of Residents}

The industrialization of tourism development, making its related services have also been rapid development, and gradually form a number of tourism-related jobs. The World Tourism Organization study pointed out that each direct employment can lead to the emergence of five indirect jobs. The rural tourism industry involves catering, accommodation, shopping, entertainment and other service industries, while the tourism industry is labor-intensive industries, you need a large number of social workers support and participation.

Ganzi Tibetan Autonomous Prefecture, relying on the rich ethnic customs and magnificent natural scenery in the Tibetan areas, has actively developed folk tourism and ecotourism, created a series of special tourism projects such as ethnic customs and village festivals, rural festivals and festivals,. Retail, transport and rural community service industry development, expand the channels for farmers to increase income, greatly solve the problem of local surplus labor employment. Specifically, Ganzi Tibetan Autonomous Prefecture tourism to promote the employment of local residents are: the use of local herdsmen with national characteristics of housing, to develop residential reception, residents receive less investment, low risk, flexible business model is conducive to the development and management of farmers. At the same time, the development of tourism, the promotion of tourism products, will attract a large number of farmers and herdsmen engaged in tourism souvenirs, handicrafts processing business, but also for the local agricultural products provide a new consumer channels and consumer groups, farmers and herdsmen in which not only Can directly get economic income, but also promote cultural exchanges and integration.

Table 4. Ganzi Tibetan Autonomous Prefecture in recent years, the new employment situation statistics.

\begin{tabular}{|c|c|c|c|c|c|c|c|c|c|}
\hline Years & 2007 & 2008 & 2009 & 2010 & 2011 & 2012 & 2013 & 2014 & 2015 \\
\hline New employment & 4547 & 4784 & 5893 & 5645 & 7040 & 7718 & 8000 & 7386 & 7475 \\
\hline
\end{tabular}

(Source: Statistical Communiqué on National Economic and Social Development of Ganzi Tibetan Autonomous Prefecture, 2007-2015)

In short, the development of tourism and consumer groups to bring the ability to aggregate the formation of land use concentration, and to promote the transfer of farmers from the primary industry to engage in the production of the second or third industry, so that farmers become high-income non-agricultural workers. Therefore, the tourism industry on the development of the population will also further promote the new urbanization of the pace of construction.

\section{Negative Effects of Tourism on Ganzi Tibetan Autonomous Prefecture}

\subsection{Over-Reliance on Tourism, New Urbanization Risk}

The tourism industry is a fragile industry, and changes in the natural, social and economic environment are likely to 
bring about fluctuations in the development of tourism. In addition, the tourism destination in the event of negative events, it will damage the image of tourist destinations, reputation and security, tourist destinations to reduce the attractiveness of tourists, the impact of tourist travel to the event of tourism needs. If the local economy and urban development over-reliance on tourism, once the tourism industry is hit, the industry is difficult to develop the town will lose its economic pillars, the regional economy is difficult to develop, employees will lose their livelihood,. Towns can not be healthy and stable development.

2008 is a very difficult year in the tourism development history of our state. Due to the spread of the "3.14" event in Lhasa and the devastating impact of the "5.12" Wenchuan earthquake, the domestic tourism market was depressed and the majority of tourist routes in Ganzi Tibetan Autonomous Prefecture were suspended. The tourism market is almost stagnant, and the tourism and related services sector is suffering a great deal. In 2008, the total annual tourism income of 777 million yuan, down $66.9 \%$, domestic tourism income of 747,516,700 yuan, down $63.5 \%$; domestic tourists 115 million people (times), down 63.5\%; inbound tourism number 16,100 people ), Down $86 \%$; foreign exchange income of 442.02 million US dollars, down $88.7 \%$.

At the same time, the state's gross domestic product and local public finance have also been affected. Thus, the impact of tourism on the development of urbanization is obvious, in the development of new urbanization process, if the transition depends on tourism, new urbanization risk.

\subsection{Tourism Industry System Is Imperfect, New Urbanization Driven Effect Is Insufficient}

Ganzi Tibetan Autonomous Prefecture tourism started late, the tourism industry system is not perfect, leading to new urbanization driven effect is insufficient. Mainly as follows:

(1) Tourism products, mining is not enough, tourism resources, the advantages and potential failed to play. The existing tourism products to the natural ecological resources of the one-time tourism products, not to achieve diversification, repeatability, high value-added leisure tourism products, the transformation of the most distinctive Kangba Tibetan national culture, ethnic customs Of the tourism connotation of mining is not enough, the advantages of resources can not be fully transformed into tourism capital advantage.

(2) Tourism product structure is relatively single, multi-level product system is not formed. Tourism, high-end tourism and leisure, business meetings, special tourism and other tourist market research is not enough, can not meet the multi-level consumer demand and the source market.

(3) The tourism industry chain has been formed, but the tourism industry structure is not perfect, most of the travel agencies are small, the number of tourist hotels, hotels grow rapidly, irrational structure, hotels, low-grade, Conditional constraints.

(4) Rural tourism has begun to take shape, but the low-grade, poor facilities, services are not standardized.

\subsection{Local Residents with Low Cultural Skills, Employment Opportunities Are Easily Occupied by Foreign Personnel Crowded}

Ganzi Tibetan Autonomous Prefecture because of long-term in the closed behind the remote ethnic minority areas, the local people's thinking is also very backward, there is "small rich that" the traditional ideas, but also afraid to take risks, in addition to operating small tourist goods shopping stalls and some Small farmhouse outside the Ganzi Tibetan Autonomous Prefecture a lot of tourism restaurants, tourist hotels, tourist goods stores are foreign businessmen to invest in business.

Many local residents because of the previous poor economic conditions, cultural concept of light, most people are short of education time, and even some people have never been a formal culture and education, cultural level and skill level is very low, many elderly people without culture, Some elderly Tibetans do not even speak Chinese, the majority of young people only have junior high school, high school education. Lack of culture and skills make it more difficult for local people to get jobs without a lot of employment, and it greatly limits the horizontal movement of farmers and herdsmen. As a result, employment opportunities were occupied by foreign personnel crowded.

\subsection{Traditional Culture Is Impacted by the Tourism Industry, and the Connotation of the City Is Lost}

The development of tourism in ethnic areas, vulnerable to the impact of tourism. Due to the extensive tourism resources, a lot of valuable tourism resources are easily destroyed under various constructions, and the tourism resources of the national historical culture and architectural art are destroyed, and the ecological vegetation and tourism environment of the local area are also very seriousdestruction.

In the process of economic and social development, the Ganzi Tibetan Autonomous Prefecture paid too much attention to the speed of economic development and the pursuit of modernization. The value and protection of traditional culture were not enough. Therefore, the excavation of traditional national culture was neglected in the process of urban construction and tourism development.. Protection and display, along with the development of tourism brought about by a large number of modern cultural ideas and foreign cultural impact, the traditional concept of Ganzi Tibetan Autonomous Prefecture and traditional culture gradually changed, the local characteristics of the city and cultural connotation is missing.In recent years, some experts and scholars in the face of the disappearance of the Tibetan traditional culture and the disappearance of the connotation of urban culture, strongly called for the protection and development of traditional culture, tourism activities and tourism cities and towns showcase national culture, innovation and national culture, Cultural and cultural changes 
in the tourism industry is still in the construction, performance, costumes, folk activities, local residents and other aspects of the concept of traditional culture and other aspects of the imperceptibly occurred, the specific manifestations of urban cultural features show a formal, traditional Cultural characteristics of decay, innovative urban cultural connotation to make it lose its authenticity.

\section{Policy Proposals on Tourism Development in Minority Areas to Promote New Urbanization}

\subsection{Tourism and Other Competitive Industries, Multi-channel to Promote the Development of New Urbanization}

Ganzi Tibetan Autonomous Prefecture uses the tourism resources and environment of rural natural landscape, pastoral scenery, agriculture, forestry, animal husbandry and fishery production, farming culture, folk culture, historical and cultural, rural ancient village style, farmer life and other factors, through scientific planning and design, For the people of the city to provide tourism, tourism, rest, vacation, entertainment, perception, fitness, shopping and other new leisure activities environment, thus forming a rural characteristics of tourism and leisure industries and economic patterns. However, it is not advisable to develop tourism to promote urbanization. The rural pastoral area of Ganzi is a place of rich tourism resources. Farming culture and nomadic culture coexist, and it is also the place where the lack of tourism development funds and tourism resources is the fastest. The better way to solve this problem is to integrate tourism development into rural Economic construction, the tourism industry and other advantages of combining industries, which is the implementation of the party Central Committee of the important steps of building a new socialist countryside.

At present, the Ganzi Tibetan Autonomous Prefecture has the advantages of plateau characteristics of ecological agriculture and animal husbandry industry, the advantages of mining industry, the characteristics of agricultural products processing industry, Tibetan medicine. Ganzi industrial development of the general idea is: the stability of the development of primary industry, the appropriate development of the secondary industry, give priority to the development of tertiary industry. To enhance the core competitiveness of the industry and sustainable development capacity as the center, take the "scientific development, innovation and development, intensive development" of the road to speed up the development and transformation of advantageous resources, vigorously promote the development of the tourism industry, promote industrial structure to "Eco-tourism, ecological agriculture and the advantages of mining and other advantages of pillar industries, and actively cultivate the Tibetan medicine, culture, a new strategic industry, reinforce the service industry". Of the basic position, to promote industrial agglomeration, to achieve industrial development, and promote resources to the economic development of a large state.

\subsection{Establish an Effective Government-Led Mechanism, so That the Tourism Industry and the New Urbanization and Coordinated Development}

In view of the outstanding problems of new urbanization in Ganzi Tibetan Autonomous Prefecture, an effective government - led mechanism should be established to coordinate the development of tourism and new urbanization.

To enhance the level of urbanization planning. Strengthen regional spatial planning, optimize urban spatial layout and shape, give full play to Ganzi Tibetan Autonomous Prefecture existing geographical advantages and national cultural advantages, reflecting the ecological environmental protection, cultural heritage, highlight the characteristics of the planning requirements. Establish and improve the planning system, strengthen the planning and implementation, and guide the orderly and healthy development of urban and rural construction.

Vigorously foster urban agglomeration, enhance the central city radiation drive function. Scientific planning, outstanding features, orderly advancement, to enhance Kangding as the center, the county and the characteristics of market towns as the focus, farmers and herdsmen village and herdsman settlements based on Ganzi Tibetan Autonomous Prefecture national characteristics of the Tibetan urban system. Strengthen the Kangding - Luding, Litang Daocheng central city functions, the development of a number of point-like county (city) central cities and towns, and enhance concentration and radiation effects.

Improve the state's large transport skeleton, full participation in regional cooperation. Increase the intensity of traffic construction, build an expressway, trunk road and railway as the skeleton, and air transport interconnected integrated transport network, and the surrounding areas to achieve interoperability, improve the level of development of the road.

Efforts to enhance the level of financial development, urban construction funds to protect the demand. Fully tap social capital, and build a bridge with financial institutions, and strive to solve the financing difficulties and other issues, the introduction of multi-channel construction funds to fully protect the urbanization process in the capital needs.

\subsection{The Establishment of Ethnic Minority Tourist Towns, and Promote the Development of Tourism Urbanization Differentiation}

From the natural ecological resources development, and strengthen the cultural integration and content mining, to the characteristics of the Kham culture, love songs culture, religious and cultural resources as well as the multi-ethnic folk cultural resources, and natural ecology, planning and diversification of products system. Relying on the "ecological Ganzi", concentrate on the construction of 
cultural connotation rich "Ganzi", "culture Ganzi", "romantic Ganzi" multi-product system. Out of a different from the characteristics of the surrounding tourist city of the road, the establishment of ethnic minority tourist towns.

In the course of the development of tourism urbanization, we should pay attention to the protection of local culture, with the unique folk culture as the foundation, vigorously develop the cultural industry, and develop to the direction of "specialized, fine, special and new". Has its own brand, a vibrant cultural industry group, the cultural industry bigger and stronger, so that the traditional culture of ethnic minority areas in the market economy under the conditions full of vitality, to be further inherited and carried forward.On the other hand, actively play the national culture in maintaining social stability, strengthen national unity in the important role. It can be said that the national culture has inherited human civilization, enhance national unity and promote social development, an important social function. In the industrialization of national cultural resources, the cultural resources to cultural products must adhere to the social and economic benefits of the unity of the double. It is necessary to follow the laws of commodity value and the law of market economy, but also follow the law of social value and cultural development laws, The relationship between the efforts to achieve social and economic benefits of the "win-win." In short, the development of tourism should be combined with the protection and transmission of ethnic culture, to avoid the development of homogeneity, the establishment of ethnic minority tourist towns.

\subsection{The Establishment of a Viable Financing Model to Accelerate the New Urbanization Process}

According to the statistics and forecasts of the relevant departments, the current total population of Ganzi Prefecture is $1,091,800$. By 2020, the population will reach 1.2 million. By 2030, the population will increase to 1.27 million. At the same time, urbanization requires industry support, 2014, the state industrial structure ratio of 24.9: 37.3: 37.8. According to Simon Kuznets research results show that the state is in the early stages of industrialization to the medium-term transition stage, urban development needs of public services, infrastructure, public goods require a lot of capital investment. At present, the state infrastructure investment continued to expand, with an average annual growth of about $10 \%$. At the same time, continue to add industrial parks, orderly land transfer, to achieve the intensive use of land. And gradually solve the housing problems into the city staff, so that the city has room to live and live, to meet the basic needs of life and to share the results of urban development.

For the Ganzi Tibetan Autonomous Prefecture, the existing supply of infrastructure is relatively backward, a series of social needs, such as: public services, public utilities and infrastructure, the masses are not fully meet the serious constraints of the Ganzi Tibetan The Overall Development Process of New Urbanization in Autonomous Prefecture. From this we can see that investment is to protect these important support for the building. Therefore, the
GanziTibetan Autonomous Prefecture need to establish a viable financing model, Ganzi Tibetan Autonomous Prefecture of economic and social development to achieve sound and fast development.

\subsection{Strengthen Training, and Promote Rural Surplus Labor to Non-agricultural Industry Orderly Transfer}

Accelerate the development of labor services from quantitative to quantitative and quality change. Improve the government-led and social participation in a combination of training system, increase training investment, innovation and training methods, co-ordination of training programs, strengthen the supervision of skills training. Improve the level of labor service development, and promote rural surplus labor to non-agricultural industry orderly transfer.

The rural surplus labor force transfer and training system can be established, and the construction of the training base should be carried out in accordance with the principle of relying on townships, relying on enterprises and the government to promote the broad participation of all sectors of society and market-oriented operation. Specifically, one is to strengthen the labor and employment sector training base, expand training capacity, making it the state employment training subject. Second, local training bases are established according to their own characteristics of development. According to the characteristics of employment in Ganzi Prefecture, the local rural surplus labor force can be transferred to employment through training in the orientation and order form. Such as white jade can be based on local characteristics of handicrafts for handicraft training, the northern Ganzi, color up, Shiqu County animal husbandry counties can train yak meat, milk processing industry workers, or the traditional dairy process training; southern Daocheng, Xiangcheng and other tourist sites Can be trained tourism products manufacturing workers, tourism service practitioners.

\section{Conclusion}

Tourism industry is a strong linkage, low barriers to entry, the economy, the population has a strong gathering effect of the industry, the development of tourism and urbanization can be easily integrated. To promote tourism in urbanization in ethnic areas have a good resource, environmental foundation and security conditions. The minority areas can choose a part of the tourism resources and the tourism resources level is high, the tourism can enter the tourism development advantage area to take the tourism industry to promote urbanization road, under the guidance and support of the government, focus on financial and material resources development priority tourism area, And promote the development of urbanization through the industrial linkage effect and agglomeration diffusion effect of tourism industry. It is noteworthy that the tourism industry to promote the development of urbanization there are certain constraints and limitations, and the need for government guidance, support and regulation to ensure that the tourism industry to promote the healthy and rapid development of urbanization. 


\section{Acknowledgements}

This project is supported by the innovative scientific research project of Southwest University for Nationalities (project number: CX2015SZ010) and Science and Technology Department of Sichuan Science and Technology Soft Science Project(project number:16RKX0385).

\section{References}

[1] GaoLijun. Chengde tourism development and urbanization relevance construction [J]. Journal of Chengde Petroleum College, 2015, 01: 90-94.

[2] Liao Yuanchang. On the Integration of Tourism and Urbanization in DehongPrefecture [J]. Journal of Yunnan Provincial Committee Party School of, 2014, 06: 125-128.

[3] Shasha, Liu Xiaobin.The Promotion Effect of Tourism in New Urbanization [J]. Travel Overview (The second half), 2015,01: $67-68+70$.

[4] BaoHongjie. The Development of Bama Tourism in Guangxi Based on the Tourism Complex Model[J].Chinese Journal of Biological Control, 2015, 01: 84-85.

[5] WangJingyu. SWOT analysis of Tourism Urbanization in Heilongjiang Province [J]. Journal of Economic Research, 2015, 05: 88-91.
[6] Bao Xiao-li, Xu Liang-hui.Study on Interactive Development of Tourism and Urbanization - A Case Study of Longyan City, Fujian Province [J]. Journal of Leshan Teachers College, 2015, 03: 72-75.

[7] Sun Ying. Study on the development of tourism towns in Anchang of Xichang under the new urbanization [D]. Chengdu University of Technology, physical geography, 2014.

[8] Zhang Jian, Li Shitai. Research on the Development Path of Rural Tourism under the Background of New Urbanization [J]. Development Research, 2015, 06: 49-53.

[9] TanHai-xia. Study on New Rural Community Construction Based on Urban and Rural Integrated Tourism Service [J]. Journal of Chinese Environmental Management Cadre College, 2015, 03: 47-50.

[10] Liu Youtang. Tourism development in national regions to interact with the urbanization construction research [J]. Journal of BBS industry and science and technology, 2013, 05:36-37.

[11] He Teng. Based on synergetics in western national region tourism urbanization development research [J]. Journal of guizhou minorities research, 2013, 01: 122-126.

[12] LeiQing. Tourism urbanization construction and interactive development research, shuhe, for example [J]. Value engineering, 2011, 25:290-291. 